\title{
Softening kinetics in the process of stress relaxation after hot deformation of HSLA steel
}

\author{
E. Kalinowska-Ozgowicz ${ }^{1}$, S. Kúdela Jr. ${ }^{2}$, K. Lenik ${ }^{1}$, W. Ozgowicz ${ }^{3 *}$ \\ ${ }^{1}$ Lublin University of Technology, Fundamentals of Technology, Nadbystrzycka 38, 20-618 Lublin, Poland \\ ${ }^{2}$ Institute of Materials \& Machine Mechanics SAS, Dúbravská cesta 9, 84513 Bratislava, Slovak Republic \\ ${ }^{3}$ Silesian University of Technology, Mechanical Engineering Faculty, Institute of Engineering Materials and \\ Biomaterials, Konarskiego 18A, 44-100 Gliwice, Poland
}

Received 12 March 2018, received in revised form 7 October 2018, accepted 15 October 2018

\begin{abstract}
The paper presents the results of investigations concerning the hot plastic deformation of HSLA steel, particularly the kinetics of static thermally activated processes. The influence of the parameters of hot deformation and the duration of isothermal holding on the process of soft annealing by the stress relaxation have been investigated. The tests were performed making use of the compression method, applying a simulator Gleeble 3800. The relaxation was tested during the isothermal holding after the hot compression of HSLA steel at the strain rate of $1.0 \mathrm{~s}^{-1}$ and temperature of $850-1200^{\circ} \mathrm{C}$. The results of softening kinetics have been gathered in static recrystallization-temperature-time (RTT) curves. It has been found that in the course of the isothermal holding of the steel there occurs a recovery and static and metadynamic recrystallization. The kinetics of these processes depends mainly on the temperature and degree of deformation of the investigated steel.
\end{abstract}

K e y w or d s: HSLA steel, stress relaxation test, high-temperature deformation, microstructure, static recrystallization

\section{Introduction}

The chemical composition of High Strength Low Alloy (HSLA) type steels, as well as the technological process of their thermomechanical treatment, decide essentially about the kind of the mechanisms of their plastic deformation and recrystallization. These determine strain hardening and softening of the steel in the course of the process and also about the mechanical properties after its termination. The knowledge of these mechanisms permits an optimal formation of the fine-grained structure of austenite in the course of high-temperature plastic deformation and also in the result of the transformation of over-cooled austenite into a ferritic-pearlitic, bainitic or martensitic structure [1-7]. The thermally activated mechanisms, mainly those of dynamic and static recrystallization, are mostly identified based on the shape of flow curves or kinetic curves and changes in the share of the recrystallized fraction in the function of isothermal holding and cooling after the hot deformation. These relations have been determined in various mechanical tests or metallographic investigations [8-14]. Different experimental approaches are used for the study and quantification of the recrystallization kinetics, i.e. direct observation methods as optical microscopy and electron backscatter diffraction and external mechanical methods, such as double deformation tests and stress relaxation tests which are based on material softening assessment. Direct measurement of the recrystallized fraction in microalloyed steels is very difficult. Mechanical testing techniques such as the double hit test and the stress relaxation test are mostly preferred. These tests allow determining the recrystallized fraction as a function of temperature in the time interval after a deformation pass [9]. Although a lot of literature data is available on the recrystallization behaviour of microalloyed steels, correlations are often difficult to be made due to the effect of different experimental setups, types of analysis

*Corresponding author: e-mail address: wojciech.ozgowicz@tlen.pl 
Table 1. Chemical composition of the tested steel (wt. \%)

\begin{tabular}{ccccccccccccc}
\hline $\mathrm{C}$ & $\mathrm{Si}$ & $\mathrm{Mn}$ & $\mathrm{P}$ & $\mathrm{S}$ & $\mathrm{Cu}$ & $\mathrm{Al}$ & $\mathrm{N}$ & $\mathrm{Nb}$ & $\mathrm{V}$ & $\mathrm{Ti}$ & $\mathrm{Fe}$ \\
\hline 0.16 & 0.29 & 1.48 & 0.030 & 0.017 & 0.049 & 0.01 & 0.0098 & 0.037 & 0.002 & 0.004 & bal. \\
\hline
\end{tabular}

and test schedules that are used to obtain this data [9]. So far, only a few comparisons between different techniques and methods were reported [15-17]. Significant discrepancies can be found between the findings of different authors. However, since these authors used different types of equipment and analyzing methods to obtain their results, it is extremely difficult to reveal the reason for the observed discrepancy. It has been found that in the course of the hot deformation of HSLA steel with micro additions of $\mathrm{Nb}, \mathrm{V}, \mathrm{Ti}$ and $\mathrm{B}$ or $\mathrm{N}$, the thermally activated mechanism liquidating strain hardening is mostly a dynamic recrystallization (DRX) or dynamic recovery (DRV), but after its termination usually a static recovery (SRV), metadynamic recrystallization (MDRX) and static recrystallization (SRX) take place. These processes can be modified by simultaneously occurring dynamic precipitation (DP) and static precipitation (SP) [18-23]. The share and range of the occurrence of these mechanisms depend mainly on the stacking fault energy (SFE) of the material and the parameters of high-temperature plastic deformation. The fine-grained structure of microalloyed HSLA steels obtained in controlled conditions of hot plastic deformation and controlled cooling affects the increase of the yield point and the resistance to cracking of many metallurgical products [5, $6,11,19]$ considerably.

The aim of the present paper is, therefore, to determine the influence of the parameters of hightemperature plastic deformation on the kinetics of thermally activated static processes, conditioning the structural state and degree of the softening of structural microalloy C-Mn-Nb steel. This was determined by the stress relaxation in compression tests on the thermomechanical simulator Gleeble 3800.

\section{Experimental procedure}

\subsection{Materials and methods}

In the investigations, C-Mn-Nb steel, type HSLA, was used, industrially cast, with a ferritic-pearlitic structure and a chemical composition specified in Table 1 .

The steel provided for the tests had the profile [240E in its crude state after hot rolling. Plastometric tests applying the method of axially symmetric hot-compression were carried out on the thermomechanical stimulator Gleeble 3800, using for this purpose cylindrical samples with a diameter of $7 \mathrm{~mm}$ and length of $8.4 \mathrm{~mm}$. The samples were preheated using the resistance method in the atmosphere Ar. The head surfaces of the samples were lubricated with graphite and interlayed with tantalum foil to reduce friction. The kinetics of static softening after hightemperatures compression was investigated making use of the method of the relaxation of stresses following the deformation to values $\varepsilon$ within the range from $0.2-0.6$ at a temperature of $800-1200^{\circ} \mathrm{C}$, applying a strain rate amounting to $\dot{\varepsilon}=1.0 \mathrm{~s}^{-1}$. The samples were austenitized for $360 \mathrm{~s}$ at a temperature of $1200{ }^{\circ} \mathrm{C}$. The process of stress relaxation was analyzed during the isothermal holding of the samples for about $10^{4} \mathrm{~s}$. After their compression, the samples were cooled in water to freeze the structural effects of high-temperature deformation, recrystallization and precipitation. Greeble's simulator is equipped with a measuring unit installed in the Hydrawedge system, permitting an accurate realization of the programmed investigations. In the course of the compression test the temperature of the sample, the value of the force of loading and the displacement of the tool were recorded with a frequency of $50 \mathrm{~Hz}$. The value of the force and displacement of the anvil constitutes the basis for the determination of the instantaneous values of the flow stress and true deformation. In the structural investigations, light and electron microscopy (TEM) was applied. Metallographic observations were performed making use of the optical microscope OLYMPUS GX71 (Japan) with a magnification of about 2000 times. To determine the microstructure of steel and its phase identification a scanning transmission electron microscope STEM Titan 80-300 (FEI) was used. The observations were realized in the range of $245-390 \mathrm{kV}$ in the classic system of operation with a definition of the picture below $0.1 \mu \mathrm{m}$ of preparation in the form of foils, applying mechanical grinding and ionic polishing.

\section{Results and discussion}

\subsection{Stress relaxation curves}

Typical examples of the recorded stress relaxation curves for the investigated micro-alloyed HSLA steel at different deformation temperatures are shown in Figs. 1 and 2, where the true stress vs log (relaxation time) after the various pre-strain is shown. On these curves, three distinct stages are to be distinguished (Fig. 1). In the first stage, the level of stresses drops 


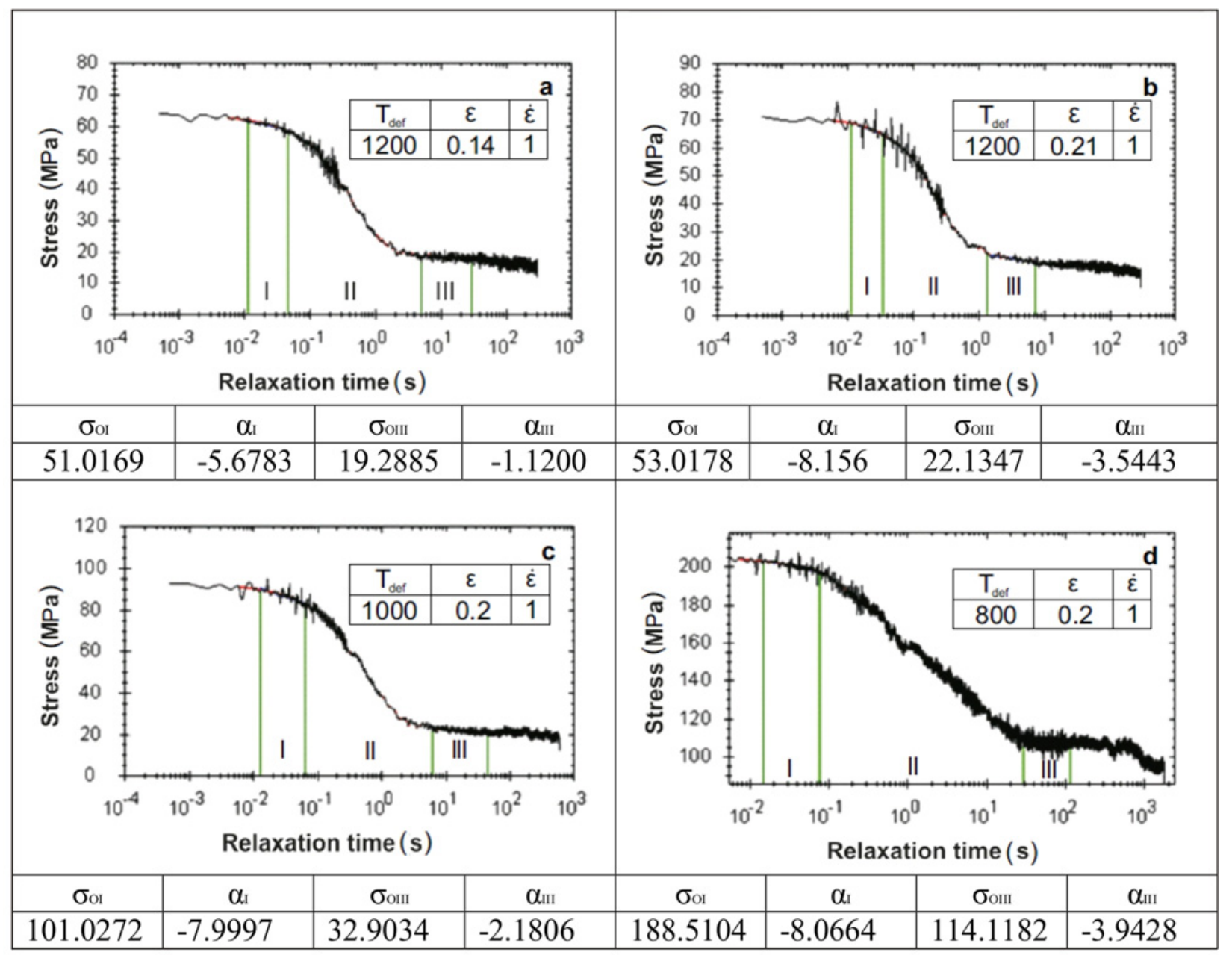

Fig. 1. Curves of the stress relaxation of C-Mn-Nb steel, recorded in the hot compression test and the method of determining the coefficients of linear equations of the stages of softening (I-III): $T_{\text {def }}$ is deformation temperature, $\varepsilon$ is strain, $\dot{\varepsilon}$ is strain rate, and $\sigma_{0}, \alpha$ are constants.

Ta b l e 2. Coefficients of linear equations of the respective stages of softening determined from the stress relaxation curves in the C-Mn-Nb steel

\begin{tabular}{|c|c|c|c|c|c|}
\hline \multicolumn{2}{|c|}{ Parameters of compression test } & \multicolumn{2}{|c|}{ Stage I } & \multicolumn{2}{|c|}{ Stage III } \\
\hline Deformation temperature $\left({ }^{\circ} \mathrm{C}\right)$ & Strain $\varepsilon$ & $\sigma_{0 \mathrm{I}}(\mathrm{MPa})$ & $\alpha_{\mathrm{I}}$ & $\sigma_{\text {OIII }}(\mathrm{MPa})$ & $\alpha_{\text {III }}$ \\
\hline \multirow[t]{5}{*}{1200} & 0.14 & 51.12 & -5.68 & 19.28 & -1.12 \\
\hline & 0.18 & 54.72 & -7.60 & 21.13 & -3.11 \\
\hline & 0.21 & 53.01 & -8.15 & 22.13 & -3.54 \\
\hline & 0.24 & 47.24 & -14.82 & 22.92 & -4.01 \\
\hline & 0.27 & 55.46 & -8.68 & 22.78 & -3.23 \\
\hline \multirow[t]{2}{*}{1100} & 0.20 & 71.60 & -9.78 & 24.62 & -2.35 \\
\hline & 0.30 & 63.98 & -24.63 & 31.86 & -6.06 \\
\hline \multirow[t]{2}{*}{1000} & 0.20 & 101.08 & -7.99 & 32.90 & -2.18 \\
\hline & 0.40 & 117.42 & -14.21 & 53.84 & -13.50 \\
\hline \multirow[t]{3}{*}{900} & 0.20 & 140.28 & -10.08 & 78.62 & -7.17 \\
\hline & 0.40 & 157.27 & -14.80 & 108.85 & -13.20 \\
\hline & 0.60 & 177.23 & -13.76 & 130.64 & -22.06 \\
\hline \multirow[t]{3}{*}{800} & 0.20 & 188.51 & -8.06 & 114.12 & -3.94 \\
\hline & 0.40 & 211.53 & -21.98 & 175.75 & -16.24 \\
\hline & 0.60 & 241.10 & -12.45 & 202.65 & -21.73 \\
\hline
\end{tabular}



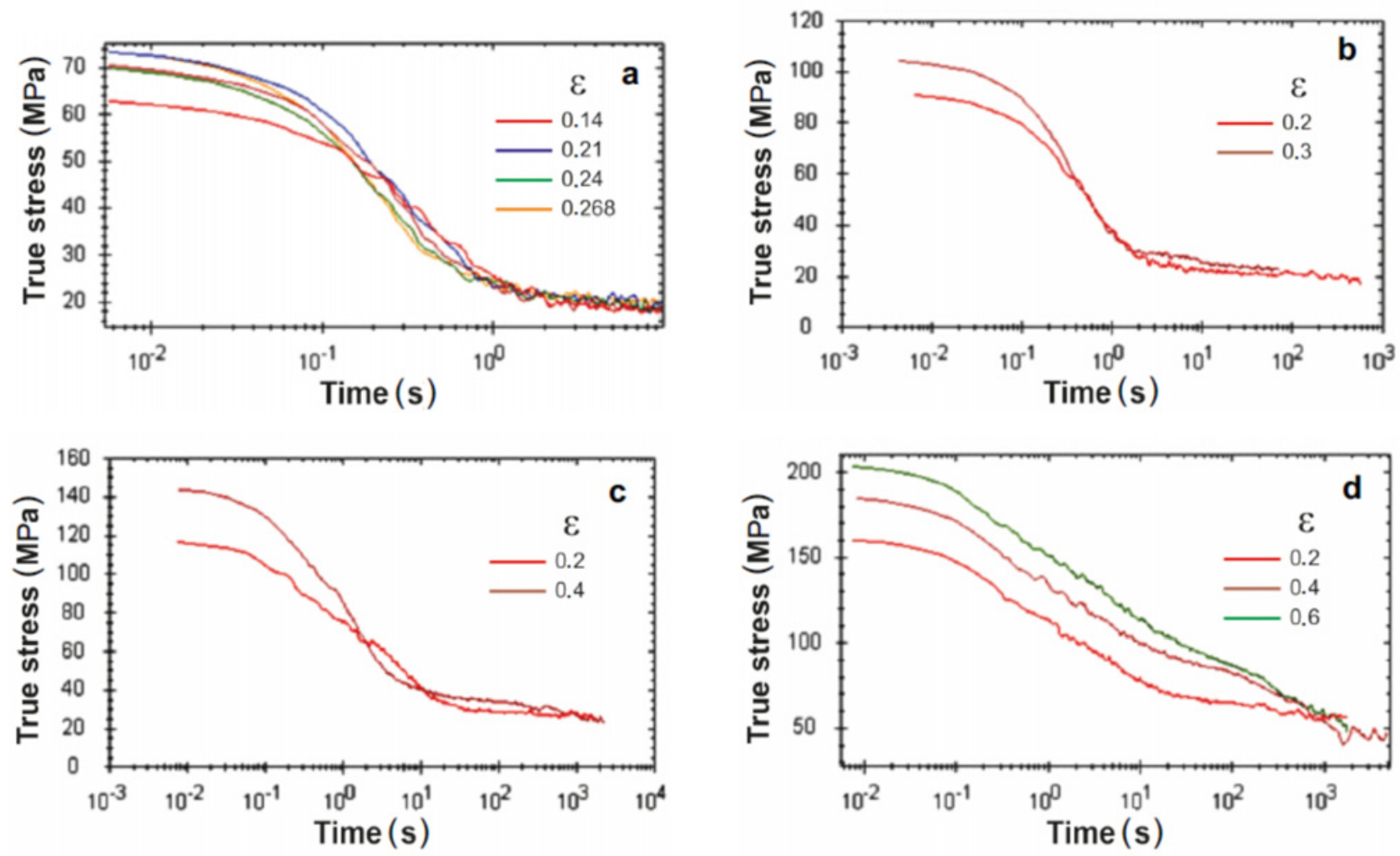

Fig. 2. The influence of the degree of deformation on the stress relaxation curves in the C-Mn-Nb steel subjected to austenitizing at $1200^{\circ} \mathrm{C}$ and compression at a) $1200^{\circ} \mathrm{C}$, b) $1100^{\circ} \mathrm{C}$, c) $1000^{\circ} \mathrm{C}$, d) $900{ }^{\circ} \mathrm{C}$ at a strain rate amounting to $1 \mathrm{~s}^{-1}$.

at a constant rate and can be described linearly. In the second one we see a sudden decrease of the stress, and in the third one, the stage of stress relaxation is similar as in the first stage, linear at a constant relatively low rate in the rate of changes of the stress. Thus, the first and third stages can be sufficiently described by the following logarithmic relation $[18,20]$ :

$$
\sigma=\sigma_{0}-\alpha \log \tau
$$

where $\sigma$ is preliminary true stress, $\tau$ is a time of relaxation after the preliminary deformation and $\sigma_{0}, \alpha$ are constant values.

Table 2 specifies the determined measured values of the coefficients in Eq. (1), resulting from the obtained curves of the stress relaxation. It has been found that in the case of the investigated parameters of high-temperature compression the inclination of the straight line in the third stage of the stress relaxation is less than in the first stage and that the values $\sigma_{0}$ increase relatively with the drop of the temperature of deformation (Table 2). The effect of the degree of preliminary deformation in the course of the hotcompression test realized at a strain rate amounting to $1.0 \mathrm{~s}^{-1}$ is illustrated by the defiltered and numerically smoothed curves of the stress relaxation (Fig. 2) within the range of the temperature of deformation from 900 to $1200^{\circ} \mathrm{C}$. The second stage of intensive softening of deformed austenite in the test steel was found to be relatively inhibited with the reduction in strain temperature and shift towards longer stress relaxation times.

Both the shape of the curves of relaxation and the results of previous investigations $[18,20]$ prove that the inclination $\alpha$ of the linear stages of relaxation $\sigma$ depends mainly on the level of the stress. This suggests that the inclination characterizes the internal properties of the material, connected with such thermally activated processes as static recovery or creeping of the material, not necessarily affected by Gleeble's device for hot-compression tests.

\subsection{Determination of recrystallization kinetics}

The initial linear segment of the stress relaxation is undoubtedly connected with a stress relaxation in austenite plastically hot-deformed due to static or metadynamic recovery (MDRV), whereas the final, i.e. the third stage, which also displays a linear dependence in spite of a considerably less inclination, is responsible for the stress relaxation already in completely softened austenite. The intensive softening of the tested steel in the time between these stages 

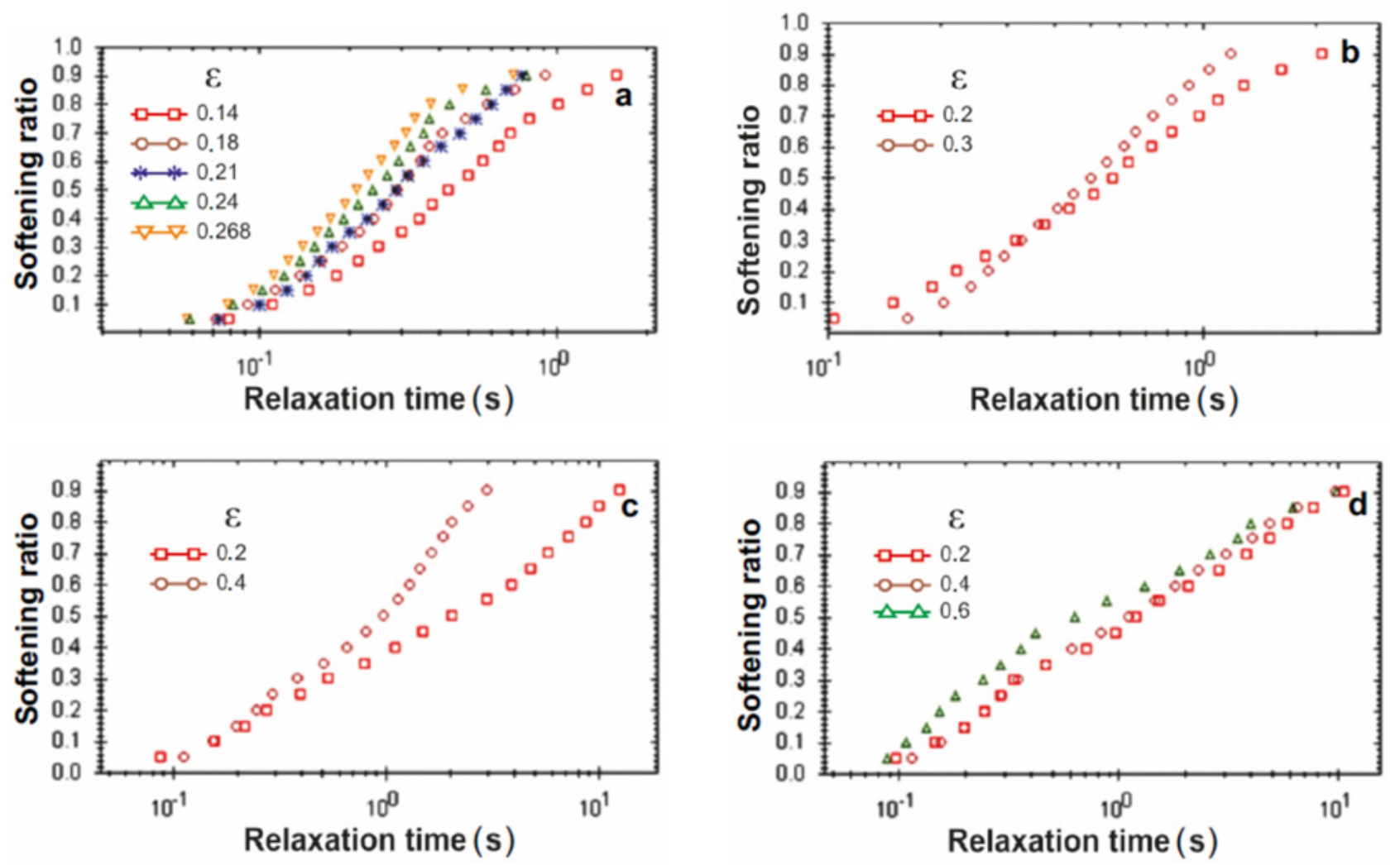

Fig. 3. The influence of the degree of deformation on the process of isothermal softening of C-Mn-Nb steel after its austenitizing at $1200^{\circ} \mathrm{C}$ and compression tests at a) $1200^{\circ} \mathrm{C}$, b) $1100^{\circ} \mathrm{C}$, c) $1000^{\circ} \mathrm{C}$, d) $900^{\circ} \mathrm{C}$ at a strain rate amounting to $1 \mathrm{~s}^{-1}$.

is brought about mainly by the process of SRX or MDRX. Assumably the partially recrystallized material indicates a different share of the strain hardened and wholly softened volumes. Therefore, the stress level in any stage of this process of softening may be expressed by the relative share of these phases. The real stress $\sigma$ as the function of time of relaxation can be expressed by the relation $[18,20]$ :

$\sigma=(1-X)\left(\sigma_{0 \mathrm{I}}-\alpha_{\mathrm{I}} \log \tau\right)+X\left(\sigma_{0 \mathrm{III}}-\alpha_{\mathrm{III}} \log \tau\right)$

where $X$ is the share of soft material and I, III are bottom indices for the first and third stage of the relaxation, respectively.

Based on the expression (2) we can determine the share $X(\tau)$ for softened material as follows:

$$
X=\frac{\left(\sigma_{01}-\alpha_{1} \log \tau\right)-\sigma}{\left(\sigma_{01}-\sigma_{0 \mathrm{III}}\right)-\left(\alpha_{1}-\alpha_{\mathrm{III}}\right) \log \tau} .
$$

The respective curves representing the fraction of soft material $X(\tau)$, determined analytically based on Eq. (3) are to be seen in the diagrams (Fig. 3). They have a sigmoidal shape which has been found to be typical of SRX. The sigmoidal shape of the respective curves corresponds distinctly to the exponential model curve corresponding to Avrami type relation [20, 21]:

$$
X=1-\exp \left[-0.693\left(t / t_{50}\right)^{n}\right]
$$

where $X$ is the fraction of the recrystallized austenite, $t_{50}$ is a time of the obtaining $50 \%$ of the recrystallized fraction, and $n$ is Avrami exponent - a constant.

The component $n$ can be determined based on Eq. (4). In the case of the kinetics SRX, it usually assumes values in the range from 1 to $2[20,21]$. The curves of the kinetics of static thermally activated processes of the investigated steel are also expressed as curves of the process of softening, and determined using hotcompression tests, are characterized by their different shapes, depending mostly on the parameters of plastic deformation (Fig. 3).

For deformation in the range $\varepsilon(0.14-0.27)$, isothermal holding after austenitizing and deformation at $1200^{\circ} \mathrm{C}$ leads to the elimination of the results of the strain hardening of the investigated steel caused by the processes SRV and SRX (Fig. 3a). To achieve a larger deformation than required to initiate dynamic recrystallization $\left(\varepsilon \geq \varepsilon_{\mathrm{cd}}\right)$ the removal of hot-work hardening results from the recovery and static recrystallization as well as metadynamic recrystallization. At the temperature of deformation amounting to $1100^{\circ} \mathrm{C}$ for $\varepsilon=0.2\left(\varepsilon<\varepsilon_{\mathrm{cd}}\right)$, the process softening of austenite is caused by SRV or SRX, whereas for $\varepsilon=0.3-$ corresponding to the value $\varepsilon_{\mathrm{cd}}$ - the stress relaxation is 

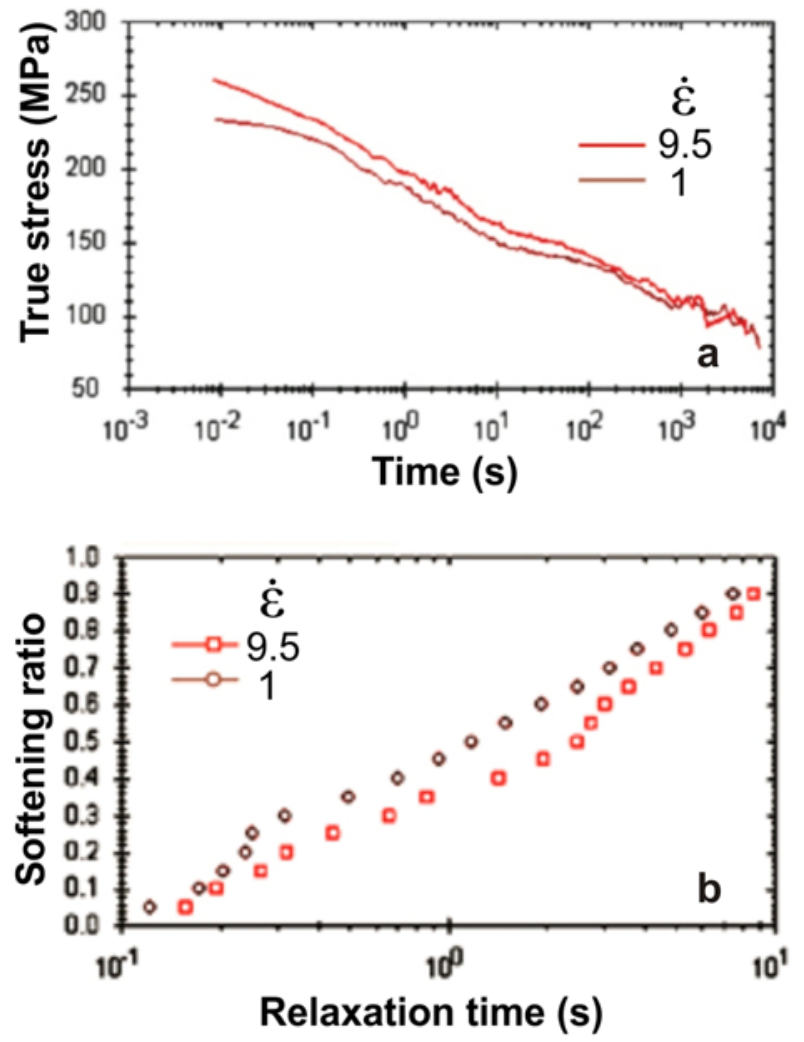

Fig. 4. The influence of the strain rate and the time of isothermal relaxation on stress relaxation (a) and the fractional softening (b) in C-Mn-Nb steel; $T_{\mathrm{A}}=1200^{\circ} \mathrm{C}, T_{\text {def }}=$ $800^{\circ} \mathrm{C}, \dot{\varepsilon}=0.4$.

caused by the process SRX (Fig. 3b). In the course of the stress relaxation after deformation in the temperature range $800-1000^{\circ} \mathrm{C}$ the occurrence of the processes SRV and SRX was observed, the share of which varies depending on the temperature and degree of deformation (Figs. 3a,b) and the strain rate (Fig. 4). The course of the curves shows that the increase in strain degree, similarly to strain rate, results not only in the intensification of the static recrystallization kinetics but also in a relative reduction in its share in favour of increasing share of metadynamic recrystallization (MDRX). This is due to the possibility of migration of former fronts of dynamic recrystallization immediately upon completion of austenite deformation, virtually with no incubation period. The density of these fronts is increasing with the increase in strain volume and strain rate. It has a significant effect on the grain refinement and substructure after metadynamic recrystallization, especially at a relatively low temperature at the end of plastic strain, as much more fronts migrate under such conditions than during hot deformation.

Moreover, on the kinetics curves determined for $\varepsilon=0.6$ in the deformation temperature range 800 $900^{\circ} \mathrm{C}$ besides probably the process SRV and SRX the

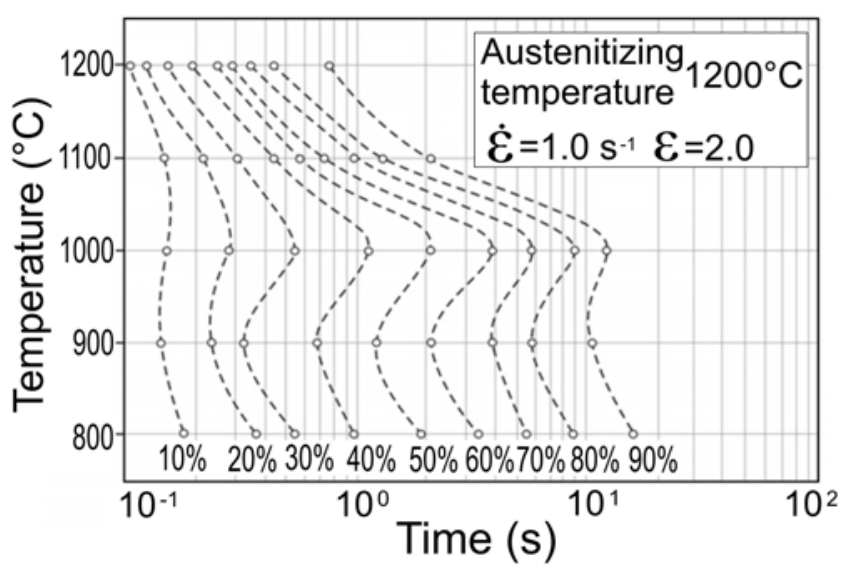

Fig. 5. Recrystallization-temperature-time (RTT) diagram for the $\mathrm{C}-\mathrm{Mn}-\mathrm{Nb}$ steel, determined by the stress relaxation testing.

stage MDRX had turned up (Figs. 3d, 4b). The analysis of the RTT (recrystallization-temperature-time) curves (Fig. 5) concerning the tested steel justifies the assumption that thermally activated processes occur in the investigated conditions of compression tests in a relatively short time of relaxation $(\tau<15 \mathrm{~s})$. After the plastic deformation and isothermal holding in the temperature range $1100-1200^{\circ} \mathrm{C}$ the process of relaxation lasts nearly $2 \mathrm{~s}$, whereas at 800 and $1100^{\circ} \mathrm{C}$ it takes respectively about 10 and $15 \mathrm{~s}$. It has also been found that the retardation of the process SRX in investigated steel is most effective at $1100^{\circ} \mathrm{C}$ after $\varepsilon=$ 0.2 .

\subsection{Metallographic analysis}

The performed metallographic investigations have permitted to determine the influence of the parameters of hot deformation and duration of relaxation on the shape and size of the primary grain of austenite previous to the transformation $\gamma \rightarrow\left(\alpha^{\prime}\right)$, conditioned by the progress of thermally activated static processes. The results of metallographic observations concerning plastically deformed steel in compression tests at a strain rate of about $1.0 \mathrm{~s}^{-1}$ in the range of the degree of deformation $\varepsilon$ from 0.14 to 0.60 and a temperature of deformation from $800-1200^{\circ} \mathrm{C}$ after its austenitizing at $1200{ }^{\circ} \mathrm{C}$ have been presented in the microphotos in Figs. 6 to 9. The procedure of thermally activated static processes after hot deformation is considerably affected by the degree and temperature of deformation (Figs. 6, 7). In tested steel deformed with $\varepsilon=0.26$ at a temperature of austenitizing $1200^{\circ} \mathrm{C}$ fine dynamically recrystallized austenite grain could be observed against the background of primary grains $\gamma$ with a size of about $75 \mu \mathrm{m}$, corresponding to the applied temperature of austenitizing (Fig. 6a). The deformation $\varepsilon=$ 

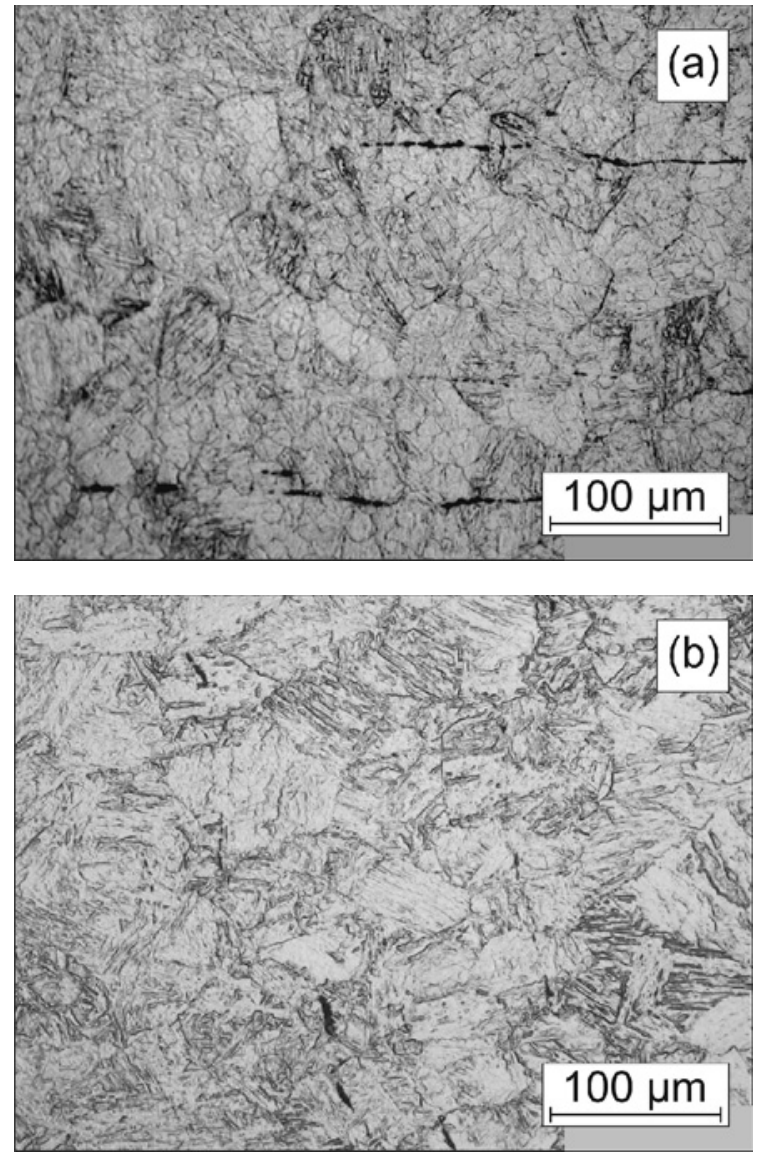

Fig. 6. The influence of the degree and temperature of deformation of $\mathrm{C}-\mathrm{Mn}-\mathrm{Nb}$ steel on the structure of the initial grains of austenite: a) $\varepsilon=0.268, T_{\text {def }}=1200^{\circ} \mathrm{C}$, b) $\varepsilon=$ $0.4, T_{\text {def }}=1000{ }^{\circ} \mathrm{C} ;\left(T_{\mathrm{A}}=1200^{\circ} \mathrm{C}, \dot{\varepsilon}=1 \mathrm{~s}^{-1}\right)$.

0.4 at $1000{ }^{\circ} \mathrm{C}$ does not allow yet in this condition an initiation of dynamic recrystallization (Fig. 6b). Such an effect in lesser degree occurs at a lower temperature of deformation $800-900^{\circ} \mathrm{C}$, or in the case of deformation $\varepsilon$ in the range of $0.2-0.6$. The revealed primary grains $\gamma$ are indicated nearly in the case of the distinct effect of hot-work hardening or dynamic recovery. The influence of the time of relaxation after hot deformation is seen in the microphoto (Fig. 8). In a compression test at $\varepsilon=0.2$ and a temperature of deformation amounting to $1000^{\circ} \mathrm{C}$ after a short time of relaxation of about $1 \mathrm{~s}$ grains of austenite vary both in size and shape, due to the effect of the initial stage of static recovery (Fig. 8a). A prolongation of the time of relaxation to about $5 \mathrm{~s}$ leads to a distinct stabilization of the structure of the grains $\gamma$, displaying features of a statically recrystallized structure (Fig. 8b). Investigations carried out in an electron transmission microscope applying thin foils, proved that the parameters of hot plastic deformation influence essentially the way of precipitation of the analyzed steel both in the course of the process and after its completion dur-
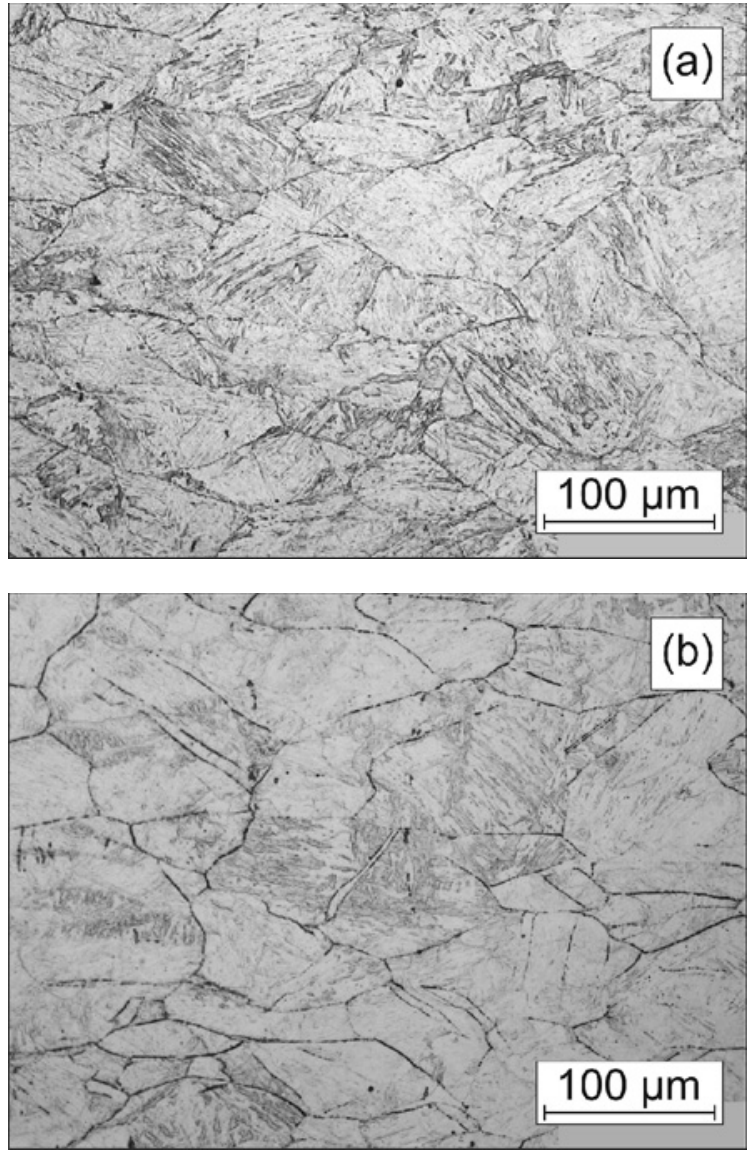

Fig. 7. The influence of the degree and temperature of deformation of C-Mn- $\mathrm{Nb}$ steel on the structure of the initial grains of austenite: a) $\varepsilon=0.6, T_{\text {def }}=900^{\circ} \mathrm{C}$, b) $\varepsilon=0.6$, $T_{\text {def }}=800^{\circ} \mathrm{C} ;\left(T_{\mathrm{A}}=1200^{\circ} \mathrm{C}, \dot{\varepsilon}=1 \mathrm{~s}^{-1}\right)$.

ing the cooling $\left(\gamma \rightarrow \alpha^{\prime}\right)$ and isothermal holding. The effects of the precipitation of metastable austenite in the matrix were tested on samples quenched in water immediately after their deformation or relaxation, using for this purpose Gleeble's installation. The effects of precipitation in $\gamma$ phase in hereditary in the martensite were identified mainly by applying the technique of electron diffraction and verified by the method of TEM observation in the dark field and supported with $\mathrm{X}$-ray microanalysis technique.

The isothermal holding of the tested steel after its hot deformation involves static processes of precipitation. After deformation at a temperature of $1100^{\circ} \mathrm{C}$ and isothermal holding for $30 \mathrm{~s}$, in the matrix of lath martensite with a large density of dislocations dispersive precipitates of carbide-nitrites could be found. There are mainly inserted in the investigated steel micro additives of $\mathrm{Nb}$ and $\mathrm{Ti}$, varying in their size and morphology. Spherical particles of precipitated $\mathrm{NbC}$ and TiN with a size of about $60 \mathrm{~nm}$ were found, among others, in the lath of martensite and at the grain boundaries of former austenite (Figs. 9, 10). At 

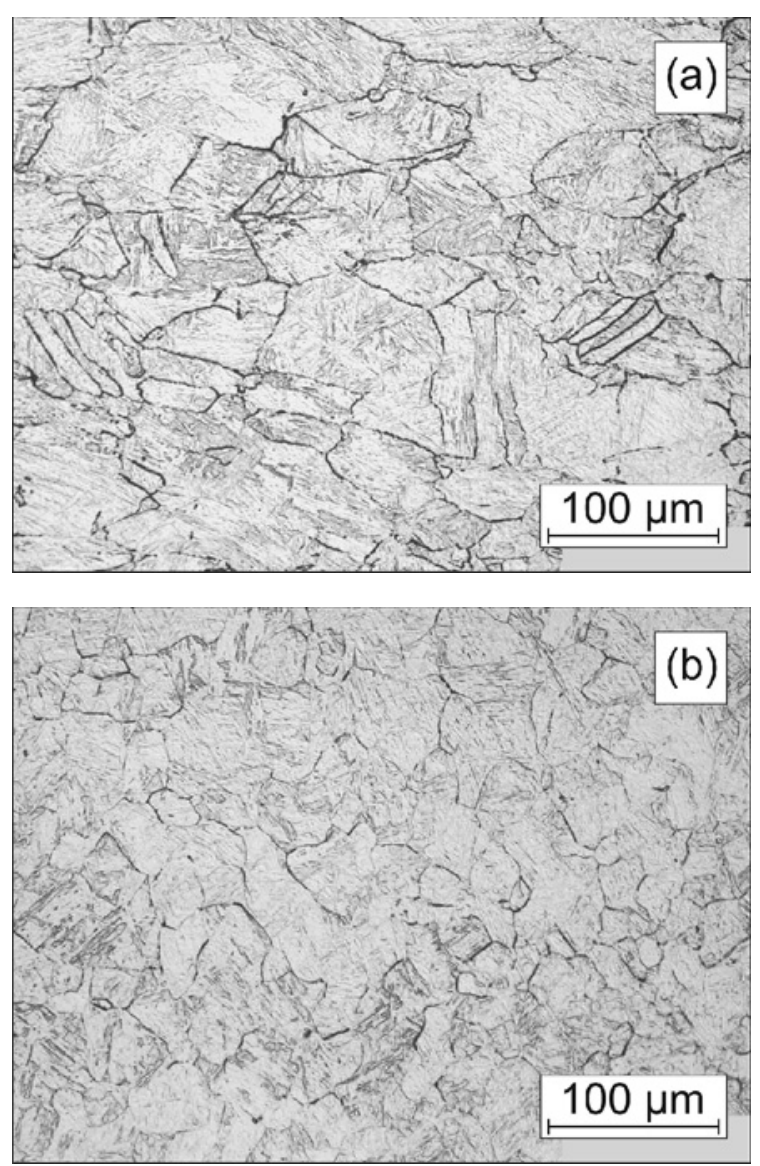

Fig. 8. The structure of the initial grains of austenite of $\mathrm{C}-\mathrm{Mn}-\mathrm{Nb}$ steel after the stress relaxation during a) $1 \mathrm{~s}$ of static recovery, b) $5 \mathrm{~s}$ of static recrystallization $\left(T_{\mathrm{A}}=1200{ }^{\circ} \mathrm{C}, T_{\mathrm{def}}=1000{ }^{\circ} \mathrm{C}, \varepsilon=0.2, \dot{\varepsilon}=1 \mathrm{~s}^{-1}\right)$.

the boundaries of the pockets of martensite, moreover, traces of residual austenite were detected. The increase in the time of isothermal holding following austenite deformation results in the formation of complex $\mathrm{Nb}$ and $\mathrm{Ti}$ carbides with various morphologies and different chemical compositions in the bainite and martensite laths (Fig. 11). In the precipitate of approx. $30 \mathrm{~nm}$ (Fig. 11, point 3), comparable niobium and titanium contents were found.

The diffraction also revealed reflexions of $\mathrm{Fe}_{3} \mathrm{C}$, suggesting the possibility of the formation of bottom bainite in the course of cooling. Similar results of phase identification in microalloy steels HSLA have been dealt with by the authors of $[3,19]$.

\section{Conclusions}

Based on the results of investigations the following conclusions may be drawn:

1. The method of the stress relaxation applied in the performed investigations permits to determine the
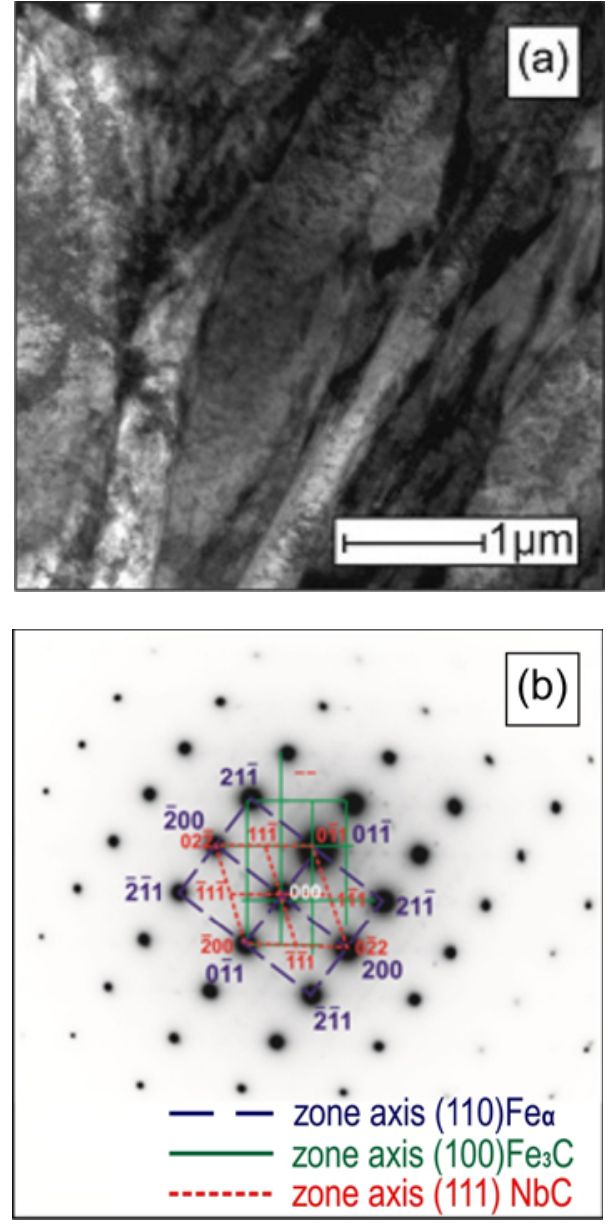

Fig. 9. The microstructure of lath martensite in the test steel with $\mathrm{NbC}$ precipitates: a) bright field, b) solution of diffraction; $T_{\mathrm{A}}=1200^{\circ} \mathrm{C}, T_{\text {def }}=1100^{\circ} \mathrm{C}, \varepsilon=0.6, \dot{\varepsilon}=$ $1.0 \mathrm{~s}^{-1}, \tau_{\mathrm{w}}=30 \mathrm{~s} /$ water.

kinetics of the softening of the analyzed microalloyed steel C-Mn-Nb, type HSLA, in the course of hotcompression tests.

2. The microstructure and thermomechanical state of the investigated steel after hot compression tests are affected mainly by thermally activated processes, particularly static recovery and static recrystallization, and also by the precipitation carbonitrides of $\mathrm{Nb}$ and Ti.

3. An increased degree of preliminary deformation of the tested steel within the range $\varepsilon$ from $0.3-0.6$ and a lowering deformation temperature below $900^{\circ} \mathrm{C}$ result in the elimination of work hardening, not only due to its recovery and static recrystallization, but also due to metadynamic recrystallization.

4. The process of static recrystallization displayed in the RTT diagram of the tested steel after its initial deformation $\varepsilon=0.2$ is most hampered during the isothermal holding at a temperature of 1000 and $800^{\circ} \mathrm{C}$. 

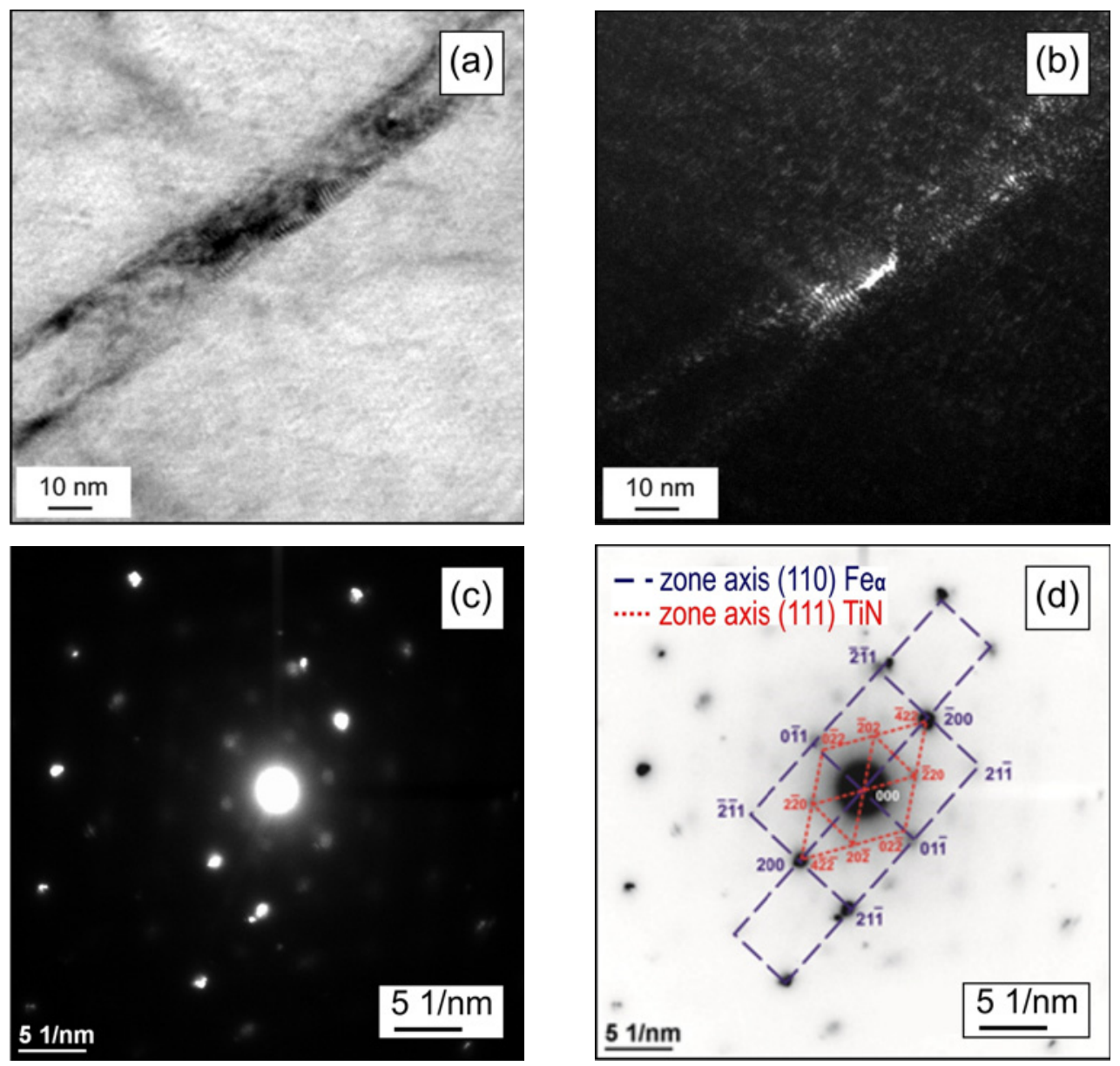

Fig. 10. Microstructure of TiN precipitate in martensite of the test steel: a) bright field, b) dark field, c) diffraction, d) solution of diffraction; $T_{\mathrm{A}}=1200^{\circ} \mathrm{C}, T_{\mathrm{def}}=1100^{\circ} \mathrm{C}, \varepsilon=0.6, \dot{\varepsilon}=1.0 \mathrm{~s}^{-1}, \tau_{\mathrm{w}}=10 \mathrm{~s} /$ water.
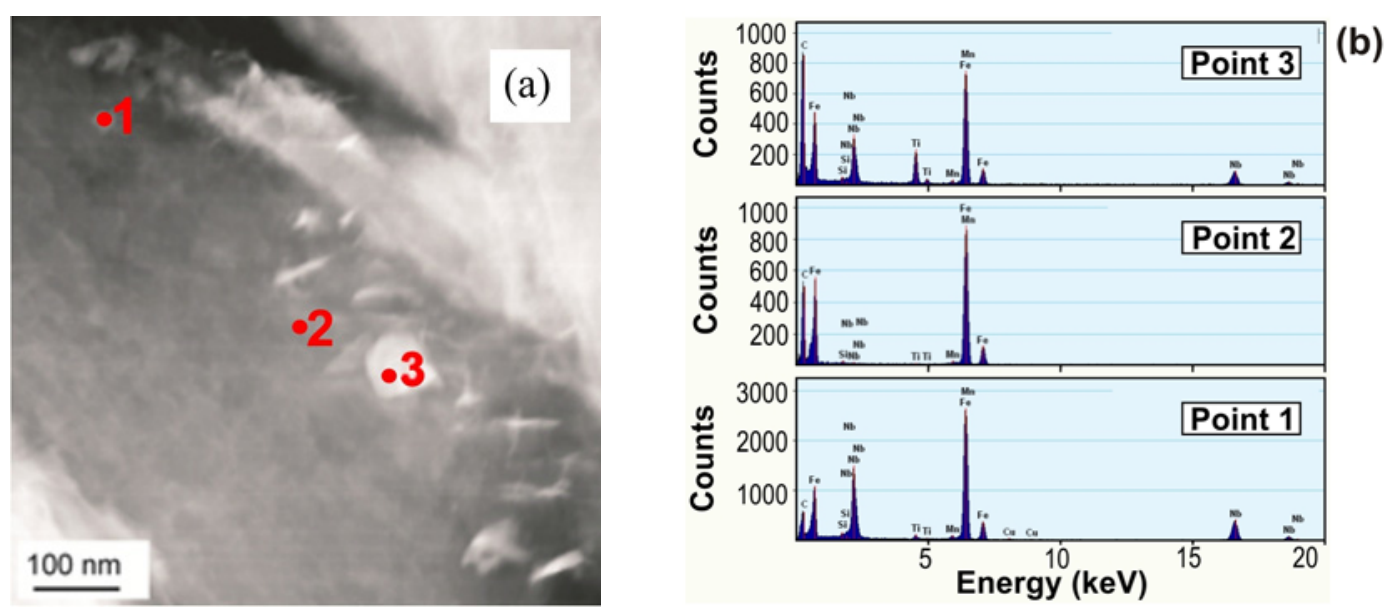

Fig. 11. Microstructure of martensite lath in the test steel with ( $\mathrm{Ti}, \mathrm{Nb}) \mathrm{C}$ precipitates: a) bright field, b) microanalysis from lath area (points $1,2,3), T_{\mathrm{A}}=1200^{\circ} \mathrm{C}, T_{\mathrm{def}}=1100^{\circ} \mathrm{C}, \varepsilon=0.2, \dot{\varepsilon}=1.0 \mathrm{~s}^{-1}, \tau_{\mathrm{w}}>180 \mathrm{~s} /$ water.

5. High-temperature deformation in the range $\varepsilon$ of $0.4-0.6$ at a temperature of $800-1200{ }^{\circ} \mathrm{C}$, as well as static recrystallization ensure a considerable grain refinement of the prior structure of the austenite to about $40 \mu \mathrm{m}$, proportional to the reduction of tempe- rature and the increasing degree of deformation.

6. The preliminary state of precipitation $\mathrm{Nb}(\mathrm{CN})$ in the tested steel during the hot deformation processes was affected by the mechanisms of strain hardening and thermally activated static processes. 
7. The curves of the stress relaxation may be used to optimize the parameters of thermomechanical treatment, as well as the processes of precipitation in microalloy steels, and also to verify experimentally the generally used equations of the kinetics of static recrystallization.

\section{References}

[1] Somani, M. C., Porter, D. A., Pyykkonen, J., Tarkka, J., Komi, J., Karjalainen, L. P.: In: Proceedings of International Conference Microalloyed Steels: Processing, Microstructure, Properties and Performance (MA'07). Pittsburg, AIST 2007, p. 95.

[2] Weng, Y., Dong, H., Gan, Y.: Advanced Steels. Part IV: Advanced HSLA steels. Berlin, Heidelberg, Metall. Ind. Press and Springer-Verlag 2011. doi:10.1007/978-3-642-17665-4

[3] He, X. L., Shang, C. J.: (Eds.): High Performance Low Carbon Bainite Steel, Chemistry, Processing Microstructure, Property and Application. Beijing, Metallurgical Industry Press 2008.

[4] Barbier, D., Chapuis, L., Jung, T.: Project Report 7 to Vanitec, Arcelor Mittal Maizieres Research, S.A, France 2009.

[5] Kostryzhev, A. G., Shahrani, A. A., Zhu, C., Ringer, S. P., Pereloma, E. V.: Mater. Sci. Forum, 753, 2013, p. 431. doi:10.4028/www.scientific.net/MSF.753.431

[6] Liu, Y. G., Liu, J., Li, M. Q.: Mater. High Temp., 34, 2017, p. 279. doi:10.1080/09603409.2017.1312771

[7] Snyder, D., Chen, E. Y., Chen, C. C., Tin, S.: Metall. and Materials Trans. A, 44, 2013, p. 479. doi:10.1007/s11661-012-1381-4

[8] Zurob, H. S., Hutchinson, C. R., Brechet, Y., Purdy, G.: Acta Mater., 50, 2002, p. 3075. doi:10.1016/S1359-6454(02)00097-6

[9] Vervynckt, S., Verbeken, K., Lopez, B., Jonas, J. J.: Int. Mater. Rev., 57, 2012, p. 187. doi:10.1179/1743280411Y.0000000013
[10] Pinheiro, I. P., Barbosa, R., Cetlin, P. R.: Mater. Sci. Eng. A, 457, 2007, p. 90. doi:10.1016/j.msea.2006.12.046

[11] Mizuguchi, T., Yamashita, M., Terada, D., Tsuji, N.: Steel Res. Int., 80, 2009, p. 627. doi:10.2374/SRI09SP049

[12] Sellars, C. M.: Ironmak. Steelmak., 38, 2011, p. 250. doi:10.1179/030192310X12706305605817

[13] Martins, C. A., Poliak, E., Godefroid, L. B., Fonstein, N.: ISIJ Int., 54, 2014, p. 227. doi:10.2355/isijinternationa1.54.227

[14] Haghdali, N., Cizek, P., Beladi, H., Hodgson, P. D.: Acta Mater., 126, 2017, p. 44. doi:10.1016/i.actamat.2016.12.045

[15] Perttula, J. S., Karjalainen, L. J.: Mater. Sci. Technol., 14, 1998, p. 626. doi:10.1179/mst.1998.14.7.626

[16] Yanagida, A., Yanagimoto, J.: Mater. Sci. Eng. A, 487, 2008, p. 510. doi:10.1016/i.msea.2007.11.031

[17] Dziubinsky, M., Husain, Z., van Haaften, W. M.: Mater. Charact., 52, 2004, p. 93. doi:10.1016/i.matchar.2004.03.006

[18] Liu, W. J., Jonas, J. J.: Metall. Trans. A, 19, 1988, p. 1403. doi:10.1007/BF02674014

[19] Hodgson, P. D.: Mathematical Modelling of Recrystallization Processing during the Hot Rolling of Steel. [PhD. Thesis]. Queensland, University of Queensland 1993.

[20] Karjalainen, L. P.: Mater. Sci. Technol., 11, 1995, p. 557. doi:10.1179/mst.1995.11.6.557

[21] Karjalainen, L. P., Perttula, J.: ISIJ Int., 36, 1996, p. 729. doi:10.2355/isijinternational.36.729

[22] Karjalainen, L. P., Perttula, J., Xu, Y., Niu, J.: In: Proceedings of 7th Int. Symp. on Physical Simulation of Casting, Hot Rolling and Welding. Tsukuba, National Research Institute for Metals 1997, p. 231.

[23] Rehman, K., Zurob, H. S.: Mater. Sci. Forum, 753, 2013, p. 417. doi:10.4028/www.scientific.net/MSF.753.417 